Original article

\title{
ANALYSIS OF PROJECT SUCCESS IN THE FUNCTION OF KNOWLEDGE MANAGEMENT IN PROJECT ORGANIZATIONS
}

\author{
Nevena Mihajlović1, Marina Apostolovska
}

\begin{abstract}
${ }^{1}$ EDUCONS University, Faculty for Project and Innovation Management, Serbia

${ }^{2}$ Union of Engineers and Technicians of Serbia, Belgrade, Serbia
\end{abstract}

Received: 7 July 2020

Revised: 21 July 2020

Accepted: 21 December 2020

\begin{abstract}
The research presented in this paper aims to show how knowledge at work affects the achievement of project benefits in organizations in southern Serbia. The subject of this research paper is the examination of the elements of knowledge management in a project in the south of Serbia. The aim of this paper is to ensure the transfer and dissemination of knowledge throughout the organization, to provide the knowledge needed to make the best decisions and business processes, to encourage and ensure the quality development of new knowledge, to support and influence the acquisition of knowledge from other sources. application and use, ensuring that new knowledge is transferred to employees who need it. The purpose is to increase the ability to create organizational value through the efficient use of knowledge. The paper presents the ANOVA test, a factor analysis for further examination of each individual research goal, with the preparation that knowledge management tools have a positive impact on project beneficiaries; knowledge retention has a positive impact on project beneficiaries; knowledge transfer positively affects the benefits of the project.
\end{abstract}

Keywords: Anova test, factor analysis, knowledge transfer, knowledge storage, knowledge management.

\section{INTRODUCTION}

Analysing previous research, we found that a small number of those organizations that transfer knowledge from one project to the next project in order to improve efficiency. In the south of Serbia, there are many of socially useful and socially responsible organizations, which led us to research on the effectiveness of knowledge management in projects.

The subject of this research paper is to examine the elements of knowledge management in the project as well as finding problems in transferring previous knowledge to new projects and overcoming these problems.

The survey was conducted in the field through surveys. In 14 organizations, 244 questionnaires were completed. After verifying the validity of the questionnaire, the data were statistically processed in the SPSS program.

The goals of the research are:

Goal 1: Is there a significant difference in the thinking of respondents of different genders?

We were interested in how respondents based on gender differences thinking about how knowledge management tools, storage and knowledge sharing affect the benefits of the project.

Goal 2: Is there a significant difference in the thinking of respondents of different age groups?

We investigated the influence of respondents' age on their thinking about how knowledge

Corresponding author. Email: nevenamihajlovic87@gmail.com

ISSN 2560-4961 (online)

Copyright $(\odot) 2020$, The Authors. Published by IPMA Serbia.

This is an open access article under the CC BY-NC 4.0 license (https://creativecommons.org/licenses/by$\mathrm{nc} / 4.0 /)$

Doi: $10.18485 /$ epmj.2020.10.2.6 
management tools, storage and knowledge sharing affect the benefit of the project.

Goal 3: Is there a significant difference in the thinking of respondents with different number of years spent in the organization?

Does the different number of years that employees spend in an organization influence respondent' thinking about how knowledge management tools, storage, and knowledge sharing affect project benefits?

Goal 4: Is there a significant difference in the thinking of respondents from different backgrounds?

Influence of education level on respondents' thinking about how knowledge management, storage and knowledge sharing tools affect project benefits.

Goal 5: Is there a significant difference in the thinking of respondents of different positions at work?

Respondents' thinking about how knowledge management, storage and knowledge sharing tools affect the benefits of a project based on its position in the organization.

Goal 6: Is there a significant difference in the thinking of respondents with different numbers of employees in the organization?

Differences in respondents' thinking about how knowledge management, storage and knowledge sharing tools affect project benefits, based on team size.

Goal 7: Is there a significant difference in the thinking of respondents at different ages of the organization?

We also wanted to examine whether the age of the organization affects respondents' thinking about how knowledge management, storage, and knowledge sharing tools affect project benefits.

Goal 8: Is there a significant difference in the thinking of respondents in different ownership structures of organizations?

How the different ownership structure of an organization influences respondents' thinking about how knowledge management tools, knowledge storage, and sharing affect project benefits.
Goal 9: Is there a significant difference in the respondents' thinking according to the type of investment project?

We consider it was very important to discover how the type of investment project affects respondents' thinking about how knowledge management tools, knowledge storage, and knowledge sharing affect project benefits.

Goal 10: Do knowledge management tools positively impact project benefit?

During the research, we wanted to determine whether management tools positively affect the benefits of the project.

Goal 11: Does knowledge storage have a positive impact on project benefit?

We also wanted to examine the impact of knowledge storage on project benefits.

Goal 12: Does knowledge sharing have a positive impact on project benefits?

In the end, we were interested in the impact of knowledge exchange on the benefits of project.

\section{THE MANNER AND PURPOSE OF KNOWLEDGE MANAGEMENT ON THE PROJECT}

As a highly responsible management function, it is tasked with effective knowledge management with the purpose of improving the way the organization uses the internal and external knowledge to improve the organization's performance. By effectively harnessing knowledge, an organization achieves significant error reduction with far better decision-making, leads to faster problem solving, and thus accelerate production and improves products and services.

Knowledge management in a project environment implies the management of activities that fill the knowledge base, creating an environment that will enable knowledge management from practice, which will result in related project-based knowledge (Reich et al., 2012).

Under the knowledge management strategy we can freely say that it means already planned knowledge management for competitive advantage. This shows us that there must be a connection and support between the knowledge management strategy and the 
business strategy, and in order to provide them with a better place in the market, production and services should be based solely on knowledge. There are two basic categorizations of knowledge management strategies. The first consists of generic knowledge management strategies that relate to the modification of knowledge from one form to another, and the second consists of generic knowledge management strategies that relate to ways to gain competitive advantage through the use of knowledge.

The foundations of knowledge management are: sharing and creating knowledge. There are tools that are used for knowledge processes. Some tools cover many different categories, while others specialize in each category. The most important thing is to use the right tools for the right knowledge management strategy. Results will only be visible if selected tools with a specific strategy are used.

Sveibi's definition of knowledge management states that "knowledge management involves the identification and analysis of available and required knowledge resources and processes to achieve organizational goals." (Sveiby, 1996).

Villegas defines knowledge management as "the simple transfer of knowledge from one person to another, with the result enabling the recipient to use the accumulated wisdom of more experienced members of the organization or group." (Villegas, 2000).

In addition to the benefits of knowledge management, there are many obstacles. Various studies on this topic have shown that insufficient understanding of the concept of knowledge management reduces its benefits; difficulties in determining the type of managed knowledge reduce its availability to users; the emergence of increasing technological limitations as a result of lack of expertise in the field of technology, lack of technological resources, lack of training programs; and the most important are the lack of employee participation, the lack of trust and the lack of a reward system for sharing knowledge, the unwillingness of employees to share knowledge.

Wunram and his colleagues believe that the obstacle can be understood as anything related to human, organizational and technological issues that make knowledge management impossible. (Wunram et al., 2002).

With the constant development of technology, the labor market requires highly skilled workers who are ready to adapt not only to changes in any environment, but also to changes in their own careers. The success of organizations in the economy based on knowledge and society will depend on the skill of animating, organizing and motivating workers on knowledge. Related to this is finding ways to acquire, preserve and share the knowledge possessed by knowledge workers among other members of the company, in which way this will lead to the creation of added value for the organization (Reich, 2007)

Satisfactory project work based on knowledge is one of the elements of achieving project goal. Cumulative knowledge from projects that have successfully achieved every single goal is the knowledge base of a project-oriented organization. The creation and use of such a knowledge base from previous projects initiates organizational learning that improves the work of the organization, which represents the benefits of the project for the organization itself.

Organizational knowledge is one of the key components of the long-term survival of an organization. Knowledge can be understood as much more than a set of information in a form from which predictions can be formed to support decision-making and action.

Garvin defines a learning organization as an organization capable of creating, collecting, and transferring knowledge, modifying its behavior as a reflection of new knowledge (Garvin, 1993).

In their further work, Garvin and others point to three main pillars of a learning organization: an environment that supports learning; concrete learning process and leadership that supports learning (Garvin, Edmondson, \& Gino, 2008).

\section{ONE-FACTOR ANALYSIS OF VARIANCE - ANOVA TEST}

Variance analysis is a statistical method that examines the effect of one or more independent 
variables on a single dependent variable. Independent variables are called influence factors and they contain multiple levels (groups) and their effect is reflected on the level of the dependent variable. When one examines the influence of one independent variable (one factor), which has three or more groups, on the dependent variable, then it is a one-factor analysis of variance. The variancebased test is more sensitive than the meanbased test, and in addition the ANOVA has a lower risk of error (Žižić et al., 2003).

In this research paper, the ANOVA test was done, with a group of questions knowledge management tools, knowledge storage, knowledge sharing and project benefits.

In ANOVA testing, certain conditions must be met (Žižić et al., 2003):

- There must be only one independent variable;

- An independent variable must have more than two values;

- There must be only one dependent variable.

In the next part of the paper, the statistical results of ANOVA testing for the first 9 research objectives will be presented. Objectives 10, 11 and 12 were set on the basis of the model, which were detailed in a previous publication of the paper "Examining the impact of knowledge elements on the achievement of project benefits in project-oriented organizations" (Mihajlović, \& Apostolovska, 2019).

- Goal 1: „Is there a significant difference in the thinking of respondents of different genders?", ANOVA testing was performed where the initial conditions are defined as follows:

$\checkmark$ Control question - Gender of the respondents was taken as an independent variable;

$\checkmark$ The values of the independent variable are: 1) male and 2) female;

$\checkmark$ One of the 18 questions from the group of questions is used as a dependent variable: knowledge management tools (AUZ), knowledge storage (SZ), knowledge exchange (RZ) and project benefit $(\mathrm{PB})$.

This test examined the possibility of a significant statistical difference between the genders of the respondents (male - female). It is important to determine whether there is a significant statistical difference in the thinking of respondents of different genders and to check whether goal 1 is met.

Testing concluded that the gender of the respondents had a significant influence on the question.

Table 1: Test of Homogeneity of Variances

\begin{tabular}{|c|c|c|c|}
\hline \multicolumn{4}{|c|}{ Test of Homogeneity of Variances } \\
\hline \multicolumn{4}{|c|}{$\begin{array}{l}\text { Video conferencing is used throughout the } \\
\text { organization to support knowledge management }\end{array}$} \\
\hline Levene Statistic & df1 & df2 & Sig. \\
\hline ,020 & 1 & 242 & \\
\hline
\end{tabular}

As the test statistic is small 0.020 and the corresponding significance level (p-value) Sig. $=0.888(>0.05)$, the assumption of equality of variance is confirmed and the ANOVA test can be used to test the null hypothesis of gender equality of the respondents.

Table 2: One-factor variance analysis

\begin{tabular}{|l|r|r|r|r|r|}
\hline \multicolumn{7}{|c|}{ ANOVA } \\
\hline \multicolumn{1}{|c|}{ Video conferencing is used throughout the organization to support knowledge management } \\
\hline & Sum of Squares & \multicolumn{1}{|c|}{ df } & Mean Square & \multicolumn{1}{c|}{ F } & \multicolumn{1}{c|}{ Sig. } \\
\hline Between Groups & 17,475 & 1 & 17,475 & 17,979 &, 000 \\
\hline Within Groups & 235,226 & 242 &, 972 & & \\
\hline Total & 252,701 & 243 & & & \\
\hline
\end{tabular}

Based on the results obtained Sig. $=0.000$ $(<0.01)$, which is shown in the ANOVA table, it was determined that the gender of the respondents had a significant impact on the specific question asked, Video conferencing is used in the organization to support knowledge management.“ 
- Goal 2: „Is there a significant difference in the thinking of respondents of different ages?", ANOVA testing was performed where the initial conditions were defined as follows:

$\checkmark$ The control question of age was taken as an independent variable;

$\checkmark$ The values of the independent variable are: 1) $\leq 25$; 2) $26-35$; 3) $36-45$; 4) $46-55$; 5) $\geq 56$;

$\checkmark$ One of the 18 questions from the group of questions is used as a dependent variable: AUZ, SZ, RZ, PB.

The testing examined the possibility of the existence of a significant statistical difference between the thinking of respondents of different ages, ie. whether the answers to the questions related to the subject research differ.

Based on the obtained results of the ANOVA test, they indicate that the age of the respondents does not have a significant impact on any of the questions within the group of questions AUZ, SZ, RZ, PB.

- Goal 3: „Is there a significant difference in the thinking of respondents with different number of years spent in the organization?", ANOVA testing was performed where the initial conditions are defined as follows:
As an independent variable, the control question was taken Years spent in the organization;

$\checkmark$ The values of the independent variable are: 1) $\leq 25$; 2) $6-10$; 3) 11-20; 4) 21-30; 5) $\geq 31$;

$\checkmark$ One of the 18 questions from the group of questions is used as a dependent variable: AUZ, SZ, RZ, PB.

The results were obtained by testing, which indicate that the assumption of equality of variance was confirmed in most cases, ie that the null hypothesis was confirmed.

The obtained results show that the years of respondents spent in the organization have a significant impact on the questions.

Table 3: Test of Homogeneity of Variances

\section{Test of Homogeneity of Variances}

Video conferencing is used throughout the organization to support knowledge management

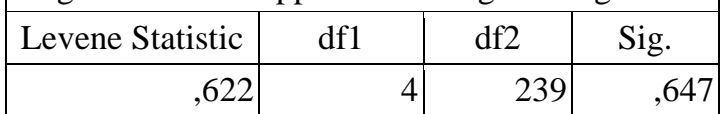

In the Test table of Homogeneity of Variances, it can be concluded that the equality of variance Sig. $=0.647(>0.05)$ is confirmed and the ANOVA test can be used to test the null hypothesis.

Table 4: One-factor variance analysis

\begin{tabular}{|l|r|r|r|r|r|}
\hline \multicolumn{7}{|c|}{ ANOVA } \\
\hline \multicolumn{7}{|c|}{ Video conferencing is used throughout the organization to support knowledge management } \\
\hline & Sum of Squares & df & Mean Square & \multicolumn{1}{|c|}{ F } & \multicolumn{1}{c|}{ Sig. } \\
\hline Between Groups & 15,982 & 4 & 3,995 & 4,034 &, 003 \\
\hline Within Groups & 236,719 & 239 &, 990 & & \\
\hline Total & 252,701 & 243 & & & \\
\hline
\end{tabular}

ANOVA test shows that respondents with different number of years spent in the organization have an influence on the question "Video conferencing is used in the organization to support knowledge management" because $\mathrm{Sig}=0.003(<0.01)$.

When testing the ANOVA test, for the five groups given, the years spent in the organization differ significantly from the question „Video conferencing is used in the organization to support meaningful management" it does not provide us with information about which groups are the most pronounced differences. Post Hoc test is used to test these differences. 
Table 5: Post Hoc

\begin{tabular}{|c|c|c|c|c|c|c|}
\hline \multicolumn{7}{|c|}{\begin{tabular}{|l} 
Multiple Comparisons \\
Video conferencing is used throughout the organization to support knowledge management
\end{tabular}} \\
\hline \multirow{2}{*}{$\begin{array}{c}\text { (I) Years spent } \\
\text { in the } \\
\text { organization }\end{array}$} & \multirow{2}{*}{$\begin{array}{c}\text { (J) Years spent } \\
\text { in the } \\
\text { organization }\end{array}$} & \multirow{2}{*}{$\begin{array}{c}\text { Mean } \\
\text { Difference } \\
\text { (I-J) }\end{array}$} & \multirow{2}{*}{ Std. Error } & \multirow{2}{*}{ Sig. } & \multicolumn{2}{|c|}{ 95\% Confidence Interval } \\
\hline & & & & & Lower Bound & Upper Bound \\
\hline \multirow[t]{4}{*}{$<=5$} & 6-10 &, 17483 &, 15570 & 868 &,- 3085 & 6582 \\
\hline & $11-20$ &,- 35338 & , 18547 & ,460 &,- 9292 & 2224 \\
\hline & $21-30$ &,- 71100 &, 24725 & ,086 & $-1,4786$ & 0566 \\
\hline & $>=31$ &,- 30909 & ,31472 & ,915 & $-1,2861$ & 6679 \\
\hline \multirow[t]{4}{*}{ 6-10 } & $<=5$ &,- 17483 &, 15570 & ,868 &,- 6582 & ,3085 \\
\hline & $11-20$ &,- 52821 & ,20158 & , 147 & $-1,1540$ & ,0976 \\
\hline & $21-30$ &,$- 88583^{*}$ & ,25955 & ,022 & $-1,6916$ &,- 0801 \\
\hline & $>=31$ &,- 48392 &, 32447 & ,695 & $-1,4912$ &, 5234 \\
\hline \multirow[t]{4}{*}{$11-20$} & $<=5$ & ,35338 &, 18547 & ,460 &,- 2224 & ,9292 \\
\hline & 6-10 &, 52821 & ,20158 & ,147 &,- 0976 & 1,1540 \\
\hline & $21-30$ &,- 35762 & ,27843 & 800 & $-1,2220$ & 5068 \\
\hline & $>=31$ &, 04429 & ,33976 & 1,000 & $-1,0105$ & 1,0991 \\
\hline \multirow[t]{4}{*}{$21-30$} & $<=5$ & ,71100 & ,24725 & ,086 &,- 0566 & 1,4786 \\
\hline & 6-10 & ,88583* & ,25955 & ,022 & ,0801 & 1,6916 \\
\hline & $11-20$ & ,35762 & ,27843 & ,800 &,- 5068 & 1,2220 \\
\hline & $>=31$ & ,40191 & ,37706 & 888 &,- 7686 & 1,5725 \\
\hline \multirow[t]{4}{*}{$>=31$} & $<=5$ & ,30909 & ,31472 & ,915 &,- 6679 & 1,2861 \\
\hline & $6-10$ & ,48392 &, 32447 & ,695 &,- 5234 & 1,4912 \\
\hline & 11-20 &,- 04429 & ,33976 & 1,000 & $-1,0991$ & 1,0105 \\
\hline & $21-30$ &,- 40191 & ,37706 & ,888 & $-1,5725$ & ,7686 \\
\hline
\end{tabular}

The results show that statistically significant differences occur between organizations where respondents have spent 6-10 years and organizations where respondents have spent 21-30 years. Thus, it can be concluded that there is a significant difference in the thinking of the respondents with different number of years spent in the organization with the question „In the organization video conferences are used to support knowledge management.“
Table 6: Test of Homogeneity of Variance

\section{Test of Homogeneity of Variances}

The overall benefits of the project exceed the company's expectations

\begin{tabular}{|c|c|c|c|}
\hline Levene Statistic & df1 & $\mathrm{df} 2$ & Sig. \\
\hline ,811 & 4 & 239 & ,519 \\
\hline
\end{tabular}

Looking at the table, it can be concluded that the equality of variances Sig. $=0.519(>0.05)$ has been confirmed and ANOVA testing is approached.

Table 7: One-factor variance analysis

\begin{tabular}{|l|r|r|r|r|r|}
\hline \multicolumn{7}{|c|}{ ANOVA } \\
\hline \multicolumn{7}{|c|}{ The overall benefits of the project exceed the company's expectations } \\
\hline & Sum of Squares & df & Mean Square & \multicolumn{1}{c|}{ F } & \multicolumn{1}{c|}{ Sig. } \\
\hline Between Groups & 9,623 & 4 & 2,406 & 4,306 &, 002 \\
\hline Within Groups & 133,537 & 239 &, 559 & & \\
\hline Total & 143,160 & 243 & & & \\
\hline
\end{tabular}


The results of the ANOVA test show that respondents with different number of years spent in the organization have an impact on the question „The overall benefits of the project exceed the company's expectations", because $\mathrm{Sig}=0.002(<0.01)$.

Although the statistics of the $\mathrm{F}$ test in the ANOVA table indicate that the five groups, the years spent in the organization differ significantly in relation to the question „The total benefits of the project exceed the company's expectations“, it does not provide information on which groups are most pronounced. The Post Hoc test is used to test these differences.

Table 8: Post Hoc

\begin{tabular}{|c|c|c|c|c|c|c|}
\hline \multicolumn{7}{|c|}{ Multiple Comparisons } \\
\hline \multicolumn{7}{|c|}{ The overall benefits of the project exceed the company's expectations } \\
\hline \multirow{2}{*}{$\begin{array}{l}\text { (I) Years spent } \\
\text { in the } \\
\text { organization }\end{array}$} & \multirow{2}{*}{$\begin{array}{l}\text { (J) Years spent } \\
\text { in the } \\
\text { organization }\end{array}$} & \multirow{2}{*}{$\begin{array}{c}\text { Mean } \\
\text { Difference } \\
(\mathrm{I}-\mathrm{J})\end{array}$} & \multirow{2}{*}{ Std. Error } & \multirow{2}{*}{ Sig. } & \multicolumn{2}{|c|}{$90 \%$ Confidence Interval } \\
\hline & & & & & Lower Bound & Upper Bound \\
\hline \multirow[t]{4}{*}{$<=5$} & $6-10$ &,- 32308 & , 11694 &, 110 &,- 6512 &, 0051 \\
\hline & $11-20$ &,- 27179 & , 13930 & ,435 &,- 6627 & ,1191 \\
\hline & $21-30$ &,$- 55789^{*}$ & , 18571 & 064 & $-1,0790$ &,- 0368 \\
\hline & $>=31$ &,- 58182 & 23638 & , 199 & $-1,2451$ &, 0815 \\
\hline \multirow[t]{4}{*}{$6-10$} & $<=5$ & ,32308 & , 11694 &, 110 &,- 0051 &, 6512 \\
\hline & $11-20$ & ,05128 & , 15140 & ,998 &,- 3736 & ,4761 \\
\hline & $21-30$ &,- 23482 & , 19494 &, 835 &,- 7818 &, 3122 \\
\hline & $>=31$ &,- 25874 & ,24370 & ,890 &,- 9426 & ,4251 \\
\hline \multirow[t]{4}{*}{$11-20$} & $<=5$ & ,27179 & , 13930 & ,435 &,- 1191 & ,6627 \\
\hline & 6-10 &,- 05128 &, 15140 & ,998 &,- 4761 & ,3736 \\
\hline & $21-30$ &,- 28610 & ,20913 & ,759 &,- 8729 & ,3007 \\
\hline & $>=31$ &,- 31002 & ,25519 &, 831 & $-1,0261$ & ,4061 \\
\hline \multirow[t]{4}{*}{$21-30$} & $<=5$ &, $55789^{*}$ & , 18571 & ,064 & ,0368 & 1,0790 \\
\hline & 6-10 & ,23482 & , 19494 &, 835 &,- 3122 & ,7818 \\
\hline & $11-20$ & ,28610 & ,20913 & ,759 &,- 3007 & ,8729 \\
\hline & $>=31$ &,- 02392 & ,28320 & 1,000 &,- 8186 & ,7708 \\
\hline \multirow[t]{4}{*}{$>=31$} & $<=5$ & ,58182 & ,23638 &, 199 &,- 0815 & 1,2451 \\
\hline & 6-10 & ,25874 & ,24370 & ,890 &,- 4251 & ,9426 \\
\hline & $11-20$ & ,31002 & ,25519 & ,831 &,- 4061 & 1,0261 \\
\hline & $21-30$ & ,02392 & ,28320 & 1,000 &,- 7708 & ,8186 \\
\hline
\end{tabular}

In this question, the difference of the mean value is for the significance level 0.1 . The results show that statistically significant differences occur between organizations where respondents spent $\leq 5$ years of work, organizations where respondents spent 21-30 years. Thus, it can be concluded that there is a significant difference in the thinking of respondents with different number of years spent in the organization on the question ,The overall benefits of the project exceed the expectations of the company."
- Goal 4: „Is there a significant difference in the thinking of respondents of different level of education?", ANOVA testing was performed where the initial conditions are defined as follows:

$\checkmark$ The control question - School readiness was taken as an independent variable;

$\checkmark$ The values of the independent variable are: 1) Basic; 2) Medium; 3) Higher; 4) High; 5) Master's / Doctorate; 
$\checkmark$ One of the 18 questions from the group of questions AUZ, SZ, RZ, $\mathrm{PB}$ is used as a dependent variable.

The reason for testing is to examine the possibility of the existence of a significant statistical difference between respondents from different level of education, ie. whether the answers to the questions related to the subject research differ, which is the connection between AUZ - knowledge management tools; SZ - knowledge storage; RZ - knowledge exchange and PB - project goals.
Testing led to the conclusion that schooling towards respondents has a significant impact on questions.

Table 9: Test of Homogeneity of Variances

\begin{tabular}{|r|c|c|c|}
\hline \multicolumn{4}{|c|}{ Test of Homogeneity of Variances } \\
\hline $\begin{array}{r}\text { The organization uses the Internet to support } \\
\text { knowledge management }\end{array}$ \\
\hline Levene Statistic & df1 & df2 & Sig. \\
\hline 1,645 & & 239 &, 164 \\
\hline
\end{tabular}

Looking at the table, it can be concluded that the equality of variances Sig. $=0.164(>0.05)$ has been confirmed and ANOVA testing is approached.

Table 10: One-factor variance analysis

\begin{tabular}{|l|r|r|r|r|r|}
\hline \multicolumn{7}{|c|}{ ANOVA } \\
\hline & Sum of Squares & \multicolumn{1}{|c|}{ Df } & Mean Square & F & \multicolumn{1}{c|}{ Sig. } \\
\hline Between Groups & 8,168 & 4 & 2,042 & 3,601 &, 007 \\
\hline Within Groups & 135,516 & 239 &, 567 & & \\
\hline Total & 143,684 & 243 & & & \\
\hline
\end{tabular}

The results of the ANOVA test show that respondents with different backgrounds have an impact on the question „The organization uses the Internet as a support for knowledge management", because Sig $=0.007(<0.01)$.

Even if the statistics of the $\mathrm{F}$ test in the ANOVA table indicate that the five groups of respondents with different education differ significantly in relation to the question „The Internet uses the Internet as a knowledge management tool", it does not provide us with information on which groups are most pronounced. A Post Hoc test is used to test the differences between each pair of groups.

Table 11: Post Hoc

\begin{tabular}{|c|c|c|c|c|c|c|}
\hline \multicolumn{7}{|c|}{ Multiple Comparisons } \\
\hline \multicolumn{7}{|c|}{ The organization uses the Internet to support knowledge management } \\
\hline \multirow{2}{*}{$\begin{array}{l}\text { (I) Educational } \\
\text { background }\end{array}$} & \multirow{2}{*}{$\begin{array}{c}\text { (J) Educational } \\
\text { background }\end{array}$} & \multirow{2}{*}{$\begin{array}{c}\text { Mean } \\
\text { Difference } \\
(\mathrm{I}-\mathrm{J})\end{array}$} & \multirow{2}{*}{ Std. Error } & \multirow{2}{*}{ Sig. } & \multicolumn{2}{|c|}{ 95\% Confidence Interval } \\
\hline & & & & & Lower Bound & Upper Bound \\
\hline \multirow[t]{4}{*}{ Basic } & Medium & -82449 & ,34102 & ,215 & $-1,8832$ & ,2342 \\
\hline & Visa & $-1,13333^{*}$ & ,36374 & ,049 & $-2,2625$ &,- 0041 \\
\hline & High & $-1,14545$ & ,40614 & ,097 & $-2,4063$ & ,1154 \\
\hline & Magistratura & $-1,60000$ & ,63001 &, 172 & $-3,5558$ & ,3558 \\
\hline \multirow[t]{4}{*}{ Medium } & Basic & ,82449 & ,34102 & ,215 &,- 2342 & 1,8832 \\
\hline & Visa &,- 30884 & ,14763 & ,360 &,- 7671 &, 1495 \\
\hline & High &,- 32096 & ,23332 & ,755 & $-1,0453$ & ,4034 \\
\hline & Magistratura &,- 77551 & ,53516 & ,717 & $-2,4369$ & ,8859 \\
\hline
\end{tabular}




\begin{tabular}{|c|c|c|c|c|c|c|}
\hline \multicolumn{7}{|c|}{ Multiple Comparisons } \\
\hline \multicolumn{7}{|c|}{ The organization uses the Internet to support knowledge management } \\
\hline \multirow{2}{*}{$\begin{array}{l}\text { (I) Educational } \\
\text { background }\end{array}$} & \multirow{2}{*}{$\begin{array}{l}\text { (J) Educational } \\
\text { background }\end{array}$} & \multirow{2}{*}{$\begin{array}{c}\text { Mean } \\
\text { Difference } \\
(\mathrm{I}-\mathrm{J})\end{array}$} & \multirow{2}{*}{ Std. Error } & \multirow{2}{*}{ Sig. } & \multicolumn{2}{|c|}{ 95\% Confidence Interval } \\
\hline & & & & & Lower Bound & Upper Bound \\
\hline \multirow[t]{4}{*}{ Visa } & Basic & $1,13333^{*}$ & ,36374 & ,049 & ,0041 & 2,2625 \\
\hline & Medium & ,30884 & , 14763 &, 360 &,- 1495 & ,7671 \\
\hline & High &,- 01212 & ,26542 & 1,000 &,- 8361 & 8119 \\
\hline & Magistratura &,- 46667 & ,54992 & ,949 & $-2,1739$ & 1,2405 \\
\hline \multirow[t]{4}{*}{ High } & Basic & 1,14545 & ,40614 & ,097 &,- 1154 & 2,4063 \\
\hline & Medium &, 32096 & ,23332 & ,755 &,- 4034 & 1,0453 \\
\hline & Visa &, 01212 &, 26542 & 1,000 &,- 8119 &, 8361 \\
\hline & Magistratura &,- 45455 & ,57884 & ,961 & $-2,2515$ & 1,3424 \\
\hline \multirow[t]{4}{*}{ Magistratura } & Basic & 1,60000 & ,63001 & ,172 &,- 3558 & 3,5558 \\
\hline & Medium & ,77551 & ,53516 & ,717 &,- 8859 & 2,4369 \\
\hline & Visa & ,46667 & ,54992 & ,949 & $-1,2405$ & 2,1739 \\
\hline & High & ,45455 &, 57884 & ,961 & $-1,3424$ & 2,2515 \\
\hline
\end{tabular}

The results show that statistically significant differences occur between respondents with primary education and respondents with higher education.

Thus, it can be concluded that the impact of school readiness differs significantly from the question „The Internet uses the Internet as a support for knowledge management."

Table 13: One-factor variance analysis

\begin{tabular}{|l|r|r|r|r|r|}
\hline \multicolumn{7}{|c|}{ ANOVA } \\
\hline \multicolumn{7}{|c|}{ Identified sources of knowledge are effectively managed on the project } \\
\hline Between Groups & Sum of Squares & df & Mean Square & F & Sig. \\
\hline Within Groups & 6,603 & 4 & 1,651 & 3,441 &, 009 \\
\hline Total & 114,660 & 239 &, 480 & & \\
\hline
\end{tabular}

The results of the ANOVA test show that respondents with different backgrounds have an impact on the question „Recognized sources of knowledge are efficiently managed on the project", because Sig $=0.009(<0.01)$.

And if the statistics of the F test in the ANOVA table indicate that the five groups of
Table 12: Test of Homogeneity of Variances

\begin{tabular}{|r|c|c|c|}
\hline \multicolumn{4}{|c|}{ Test of Homogeneity of Variances } \\
\hline Identified sources of knowledge are effectively \\
managed \\
on the project
\end{tabular}

Looking at the table, it can be concluded that the equality of variances Sig. $=0.266(>0.05)$ has been confirmed and ANOVA testing is approached. respondents with different education differ significantly in relation to the question „Recognized sources of knowledge are efficiently managed on the project", it does not provide us with information between which groups are most pronounced. A Post Hoc test is used to test the differences between each pair of groups. 
Table 14: Post Hoc

\begin{tabular}{|c|c|c|c|c|c|c|}
\hline \multicolumn{7}{|c|}{$\begin{array}{l}\text { Multiple Comparisons } \\
\text { Identified sources of knowledge are effectively managed on the project }\end{array}$} \\
\hline \multirow{2}{*}{$\begin{array}{l}\text { (I) Educational } \\
\text { background }\end{array}$} & \multirow{2}{*}{$\begin{array}{l}\text { (J) Educational } \\
\text { background }\end{array}$} & \multirow{2}{*}{$\begin{array}{c}\text { Mean } \\
\text { Difference } \\
(\mathrm{I}-\mathrm{J})\end{array}$} & \multirow[b]{2}{*}{ Std. Error } & \multirow[b]{2}{*}{ Sig. } & \multicolumn{2}{|c|}{$95 \%$ Confidence Interval } \\
\hline & & & & & Lower Bound & Upper Bound \\
\hline \multirow[t]{4}{*}{ Basic } & Medium &,- 92755 & ,31368 & ,071 & $-1,9014$ &, 0463 \\
\hline & Visa & $-1,06667^{*}$ & ,33458 & 041 & $-2,1053$ &,- 0280 \\
\hline & High & $-1,07273$ & ,37358 & ,087 & $-2,2325$ &, 0870 \\
\hline & Magistratura & $-1,80000^{*}$ & ,57950 &, 050 & $-3,5990$ &,- 0010 \\
\hline \multirow[t]{4}{*}{ Medium } & Basic & ,92755 & ,31368 & ,071 &,- 0463 & 1,9014 \\
\hline & Visa &,- 13912 & , 13579 & ,902 &,- 5607 & ,2824 \\
\hline & High &,- 14518 & ,21462 & ,977 &,- 8115 &, 5211 \\
\hline & Magistratura &,- 87245 & ,49226 & ,536 & $-2,4007$ & ,6558 \\
\hline \multirow[t]{4}{*}{ Visa } & Basic & $1,06667^{*}$ & ,33458 & ,041 & ,0280 & 2,1053 \\
\hline & Medium &, 13912 & , 13579 & ,902 &,- 2824 & ,5607 \\
\hline & High &,- 00606 &, 24414 & 1,000 &,- 7640 &, 7519 \\
\hline & Magistratura &,- 73333 &, 50583 & ,717 & $-2,3037$ &, 8370 \\
\hline \multirow[t]{4}{*}{ High } & Basic & 1,07273 & ,37358 & ,087 &,- 0870 & 2,2325 \\
\hline & Medium &, 14518 & ,21462 & ,977 &,- 5211 &, 8115 \\
\hline & Visa & ,00606 & ,24414 & 1,000 &,- 7519 &, 7640 \\
\hline & Magistratura &,- 72727 & ,53244 & ,760 & $-2,3802$ & ,9256 \\
\hline \multirow[t]{4}{*}{ Magistratura } & Basic & $1,80000^{*}$ & ,57950 & ,050 & ,0010 & 3,5990 \\
\hline & Medium &, 87245 & ,49226 & ,536 &,- 6558 & 2,4007 \\
\hline & Visa & ,73333 & ,50583 & ,717 &,- 8370 & 2,3037 \\
\hline & High & ,72727 & ,53244 & ,760 &,- 9256 & 2,3802 \\
\hline
\end{tabular}

The results show that statistically significant differences occur between respondents with primary education and respondents with higher education, as well as among respondents with a master's degree. Thus, it can be concluded that the impact of schooling differs significantly from each other in the question „Recognized sources of knowledge are effectively managed on the project".

- Goal 5: „Is there a significant difference in the thinking of the respondents of different positions at work?", ANOVA testing was performed where the initial conditions are defined as follows:

$\checkmark$ The control question-Position on the project was taken as an independent variable;

$\checkmark$ The values of the independent variable are: 1) Manager; 2) Worker; 3) Support staff;

$\checkmark$ One of the 18 questions of the group of questions is used as a dependent variable: AUZ, SZ, RZ, PB
The reason for testing is to examine the possibility of the existence of a significant statistical difference between respondents with different positions at work, ie. whether the answers to the questions related to the subject research differ.

Testing came to the conclusion that the position on the project with the respondents has a significant impact on the question.

Table 15: Test of Homogeneity of Variances

\section{Test of Homogeneity of Variances}

The project generates a lot of new knowledge, methods and innovations

\begin{tabular}{|c|c|c|c|}
\hline Levene Statistic & df1 & df 2 & Sig. \\
\hline ,276 & 2 & 241 & ,759 \\
\hline
\end{tabular}

Looking at the table, it can be concluded that the equality of variances Sig. $=0.759(>0.05)$ has been confirmed and ANOVA testing is approached. 
Table 16: One-factor variance analysis

\begin{tabular}{|l|r|r|r|r|r|}
\hline \multicolumn{7}{|c|}{ ANOVA } \\
\hline \multicolumn{7}{|c|}{ The project generates a lot of new knowledge, methods and innovations } \\
\hline & Sum of Squares & df & Mean Square & \multicolumn{1}{c|}{ F } & \multicolumn{1}{c|}{ Sig. } \\
\hline Between Groups & 4,014 & 2 & 2,007 & 4,952 &, 008 \\
\hline Within Groups & 97,674 & 241 &, 405 & & \\
\hline Total & 101,689 & 243 & & & \\
\hline
\end{tabular}

The results of the ANOVA test show that the respondents' different positions at work have an impact on the question „The project generates a lot of new knowledge, methods and innovations", because $\mathrm{Sig}=0.008(<0.01)$.

And if the statistics of the F test in the ANOVA table indicate that the three groups of respondents with different positions on the project differ significantly in relation to the question ,The project generates a lot of new knowledge, methods and innovations", it does not provide information on which groups are most pronounced. A Post Hoc test is used to test the differences between each pair of groups.

Table 17: Post Hoc

\begin{tabular}{|l|l|r|r|r|r|r|}
\hline \multicolumn{7}{|c|}{ Multiple Comparisons } \\
\hline \multicolumn{7}{|c|}{ The project generates a lot of new knowledge, methods and innovations } \\
\hline $\begin{array}{l}\text { (I) Position } \\
\text { on the } \\
\text { project }\end{array}$ & $\begin{array}{l}\text { (J) Position } \\
\text { on the } \\
\text { project }\end{array}$ & $\begin{array}{c}\text { Mean } \\
\text { Difference } \\
\text { (I-J) }\end{array}$ & Std. Error & Sig. & Lower Bound & Upper Bound \\
\hline Manager & Worker &,- 24720 &, 16974 &, 348 &,- 6653 &, 1709 \\
\cline { 2 - 8 } & Staff &, 80000 &, 40264 &, 141 &,- 1917 & 1,7917 \\
\hline \multirow{2}{*}{ Worker } & Manager &, 24720 &, 16974 &, 348 &,- 1709 &, 6653 \\
\cline { 2 - 8 } & Staff & $1,04720^{*}$ &, 36999 &, 019 &, 1359 & 1,9585 \\
\hline \multirow{2}{*}{ Staff } & Manager &,- 80000 &, 40264 &, 141 & $-1,7917$ &, 1917 \\
\cline { 2 - 7 } & Worker & $-1,04720^{*}$ &, 36999 &, 019 & $-1,9585$ &,- 1359 \\
\hline *. The mean & difference is significant at the 0.05 level. \\
\hline
\end{tabular}

The results show that statistically significant differences occur between working class respondents and support staff. So, it can be concluded that the influence of the position on the project differs significantly from the question „The project generates a lot of new knowledge, methods and innovations."

- Goal 6: „Is there a significant difference in the thinking of respondents with different numbers of employees in the organization?", ANOVA testing was performed where the initial conditions are defined as follows:

$\checkmark$ As an independent variable, the control question was taken Number of employees in the organization;

$\checkmark$ The values of the independent variable are: 1) $\leq 10$; 2) 11-50; 3) 51-250 4) $\geq 250$; $\checkmark$ One of the 18 questions from the group of questions is used as a dependent variable: AUZ, SZ, RZ, PB.

The reason for testing is to examine the possibility of the existence of a significant statistical difference between respondents with different numbers of employees, ie. whether the answers to the question related to the subject research differ, which is the connection between AUZ - knowledge management tools; SZ - knowledge storage; RZ - knowledge exchange and $\mathrm{PB}$ - project goals.

The testing concluded that the number of employees in the organization has a significant impact on the questions:

AUZ 1: „The organization uses the Internet to support knowledge management?" 
AUZ 2: „The organization uses an electronic documentation management system to support knowledge management?"

AUZ 3: „Search software is used in the organization to support knowledge management?"

SZ 4: „Useful ideas and new knowledge are stored and periodically updated on the project?"

SZ 5: „Knowledge storage is one of the important goals of the project?"

- Goal 7: „Is there a significant difference in the thinking of the respondents at different ages of the organization?", ANOVA testing was performed where the initial conditions are defined as follows:

$\checkmark$ The control question - Age of the organization was taken as an independent variable;

$\checkmark$ The values of the independent variable are: 1) $\leq 5$; 2) $6-10$; 3) 11 20; 4) 21-30; 5) $\geq 31$;

$\checkmark$ One of the 18 questions from the group of questions is used as a dependent variable: AUZ, SZ, RZ, PB.

This test aims to examine the possibility of the significance of the statistical difference between the "Chronological Age of the Organization", ie whether the answers to the questions related to the subject research differ significantly.

In this paper, the table of the Post Hoc test does not show one group of chronological age of the organization (21-30 years) because we did not find such an organization.

Testing concluded that the age of the organization has a significant impact on the questions:

AUZ 1: „The organization uses the Internet to support knowledge management?"“

AUZ 3: „The organization uses software and search to support knowledge management?"“

PB 7: „The project generates a lot of new knowledge, methods and innovations?"

PB 8: „The overall benefits of the project exceed the company's expectations?"

PB 9: „The project gives excellent results and positive outcomes?“
- Goal 8: „Is there a significant difference in the thinking of the respondents with different ownership structure of organizations?"“, ANOVA testing was performed where the initial conditions are defined as follows:

$\checkmark$ The control question-Ownership structure of the organization was taken as an independent variable;

$\checkmark$ The values of the independent variable are: 1) Domestic; 2) Foreign ownership; 3) Mixed ownership;

$\checkmark$ One of the 18 questions from the group of questions is used as a dependent variable: AUZ, SZ, RZ, PB.

This test aims to determine whether there is a significant statistical difference between the „Ownership structure of the organization“, ie whether the answers and questions related to the research in question differ.

In goal 8, we will not present the Post Hoc test because in this research the ownership structures of the organization (domestic and foreign ownership), we did not have the opportunity to have respondents from a mixed ownership structure.

Testing concluded that different ownership structures did not have a significant impact on the issue.

- Goal 9: „Is there a significant difference in the respondents' thinking according to the type of investment project?", ANOVA testing was performed where the initial conditions are defined as follows:

$\checkmark$ The control question - Type of investment project was taken as an independent variable;

$\checkmark$ The values of the independent variable are: 1) Buildings; 2) Infrastructure facilities; 3) Equipment 4) Other;

$\checkmark$ One of the 18 questions from the group of questions is used as a dependent variable: AUZ, SZ, RZ, PB. 
This test aims to determine whether there is a significant statistical difference between the „Type of investment project of the organization", or whether the answers to the questions related to the research in question differ.

The testing concluded that the respondents' thinking about the type of investment project has a significant impact on the following questions:

SZ 3: „Useful ideas and new knowledge are stored and periodically updated on the project?"“

RZ 2: „Members of different sectors in the organization exchange knowledge with the aim of better project implementation?"“

\section{STATISTICAL ANALYSIS OF THE RESEARCH MODEL}

The methodology used for statistical analysis is SEM-Structural Equation Modeling. While the software programs SPSS (SPSS-Statistical Package for the Social Sciences) and LISREL (LISREL-Lineral Structural Relationship) were used for calculation and data analysis.

\subsection{Reliability and validity of the research model}

To determine the reliability of the measurement scale, an exploratory factor analysis (EFA) was performed, which was used to examine the one-dimensionality of groups of questions in the considered research model. The obtained results are shown in Table 18.

Table 18: Results of EFA and CFA statistics for the research measurement model

\begin{tabular}{|c|c|c|c|c|c|c|}
\hline \multirow[b]{3}{*}{ Group } & \multirow[b]{3}{*}{ Variable } & \multirow{2}{*}{\multicolumn{2}{|c|}{$\begin{array}{l}\text { Exploratory Factor Analysis } \\
\text { PCA }\end{array}$}} & \multicolumn{3}{|c|}{ Exploratory Factor Analysis } \\
\hline & & & & Reliability & \multicolumn{2}{|c|}{ Convergent validity } \\
\hline & & $\begin{array}{l}\text { that can be } \\
\text { described by a } \\
\text { one-dimensional } \\
\text { factor }\end{array}$ & $\begin{array}{l}\text { Factor } \\
\text { load }\end{array}$ & $\begin{array}{l}\text { Cronbach } \\
\text { alpha }\end{array}$ & $\begin{array}{l}\text { Factor } \\
\text { load }\end{array}$ & t-value \\
\hline \multirow{6}{*}{ AUZ } & & 70.442 & & 0.884 & & \\
\hline & AUZ1 & & 0.800 & & 0.57 & $13.35 * *$ \\
\hline & AUZ2 & & 0.922 & & 0.80 & $18.24 * *$ \\
\hline & AUZ3 & & 0.936 & & 0.88 & $19.50 * *$ \\
\hline & AUZ4 & & 0.613 & & 0.55 & $8.82 *$ \\
\hline & AUZ5 & & 0.883 & & 0.77 & $16.49 * *$ \\
\hline \multirow{6}{*}{ SZ } & & 80.871 & & 0.940 & & \\
\hline & SZ1 & & 0.848 & & 0.42 & $11.22 * *$ \\
\hline & SZ2 & & 0.897 & & 0.50 & $12.81 * *$ \\
\hline & SZ3 & & 0.900 & & 0.77 & $21.04 * *$ \\
\hline & SZ4 & & 0.909 & & 0.78 & $21.30 * *$ \\
\hline & SZ5 & & 0.939 & & 0.63 & $16.16^{* *}$ \\
\hline \multirow{6}{*}{$\mathbf{R Z}$} & & 72.616 & & 0.905 & & \\
\hline & RZ1 & & 0.665 & & 0.31 & $7.45^{* *}$ \\
\hline & RZ2 & & 0.885 & & 0.61 & $15.16 * *$ \\
\hline & RZ3 & & 0.929 & & 0.81 & $21.83 * *$ \\
\hline & RZ4 & & 0.928 & & 0.80 & $21.80 * *$ \\
\hline & RZ5 & & 0.826 & & 0.47 & $11.10 * *$ \\
\hline \multirow{4}{*}{ PB } & & 69.071 & & 0.756 & & \\
\hline & PB7 & & 0.849 & & 0.58 & $15.20 * *$ \\
\hline & PB8 & & 0.705 & & 0.39 & $7.82 * *$ \\
\hline & PB9 & & 0.881 & & 0.50 & $13.78 * *$ \\
\hline
\end{tabular}

One of the methods used in EFA analysis is PCA-Principal Component Analysis. 18 questions were analyzed and divided into 4 groups. First of all, it is necessary to confirm whether the data set is suitable for factor analysis. This is confirmed by checking the value of the Kaiser-Meyer-Olkin Measure of Sampling Adequace (KMO) indicator, the 
value must be equal to or greater than 0.6 and whether the value of the Barlett's Test of Sphericity indicator is significant (ie that the Sig. $\leq 0.05$ value).

For the first group of questions, ie AUZ, the $\mathrm{KMO}$ indicator is 0.827 and Bartlet's indicator is significant (Sig. $=0.000$ ), so the factor analysis is justified. For the second group of questions, the NW CMO is 0.801 , and Bartler's indicator is significant because the value (Sig. $=0.000$ ). In the third group of questions, the RZ KMO is 0.779 and the factor analysis is a justified value of Sig. is the same as in the first two groups. In the last group of questions PB $\mathrm{KMO}$ is 0.630 and Barterl's test is the same as in the previous groups of questions.

As for the Kaiser criterion, we consider only components whose characteristic value is greater than or equal to 1 . In the table Total Variance Explained we can see how many components meet the Kaiser criterion. For the first group of questions we have one value which is $70.442 \%$ of the cumulative. In the second group of questions we also have a value of $80.871 \%$. In the third and fourth groups, there is one value each and they amount to $72.616 \%$ and $69.071 \%$. It happens that the number of components that meet the Kaiser's criterion is too large, so it is mandatory to review the pass diagram (Screeplot) that SPSS also drew. It can be clearly seen on the graph that for each group of questions there is one factor set with a value greater than 1 .

From the obtained results of factor analysis (PCA) it can be concluded that one dimensionality was confirmed in all 4 groups that were set in the research model.

The factor load is in the range from 0.613 to the lowest value to 0.939 to the highest value, which is above the recommended value of 0.4 , based on the recommendations of the authors (Žižić et al., 2003). Based on the obtained values, it can be concluded that all groups of questions can be reliably described using all defined questions in the paper.

In order to confirm the reliability of the Cronbach's alpha coefficient, it is necessary that the obtained coefficients are ideally more than 0.7. Based on the obtained results shown in Table 18, we can see that the values meet the set conditions.
The convergent validity of the research model was achieved on the basis of the obtained values for factor load and t-value, which are shown in Table 18.

\section{CONCLUSION}

Knowledge is the foundation, the strategic growth of an organization. Knowledge management is the process of creating, collecting, storing, and using explicit and implicit knowledge to achieve better organizational performance. With the daily encounter with the issue of knowledge management, organizations are increasingly aware that they must solve problems by establishing an organizational culture of knowledge sharing, ensuring the up-to-date information, harmonizing the knowledge management system and ensuring the balance of the knowledge management system. If invested wisely in knowledge management, organizations can achieve significant benefits.

The research conducted on the territory of southern Serbia analyzed the effects of knowledge elements on the achievement of project benefits in project-oriented organizations. The paper presents certain goals that needed to be examined and confirmed their validity, as well as explains the obtained data. This paper deals in detail with the analysis of the impact of knowledge on project work in order to benefit from projects in micro, small and medium enterprises in southern Serbia. The analysis was performed using software packages SPSS and LISLER and based on the obtained data we concluded: differences between employees (Gender; Age; Years spent in the organization; Level of education; Position at work); as well as differences between organizations (Size of organization; Age of organization; Ownership structure; Type of investment project) affect respondents' different thinking about the use of AUZ, SZ, $\mathrm{RZ}$ and PB. All these differences proved to be the impossibility of using previous knowledge on new projects. As one of the problems in the south of Serbia, we see the fact that the organizations that exist here have branches from other, more developed areas and as such do not provide the possibility of employing highly educated staff. We also concluded that I can thank the easily accessible, cheap labor for the longevity of this organization. It is 
interesting that the structure of the company is mostly domestic, but there are also several foreign-owned organizations, which can be taken as a positive result for the underdeveloped south of Serbia. The ANOVA test tells us that a statistically significant difference in the respondents' answers occurs in: gender of the respondents; years spent in the organization; qualifications of employees in the organization, which is obvious, employees with a lower level of education have a different opinion regarding knowledge at work than employees who have a higher level of education in that organization; positions at work, research leads to the fact that the position of the workplace plays a significant role in accessing the database and expressed the lack of interest of workers in lower positions to improve new methods and innovations of knowledge; the data show us that the number of employees in the organization also has a significant impact, large organizations offer their employees greater opportunities (internet, access to the knowledge storage database with periodic updates); the age of the organization, which is obvious, older organizations have larger knowledge bases, more experience in developing knowledge management methods; types of investment project.

Organizations should continuously improved their knowledge to reduce uncertainty in the improvement and anticipation, of what is achieved through the organizational learning process, and only such an organization is made up of members capable, of not only perceiving, but also anticipating future changes in the work environment and thus identifying strategies for adopting these changes and implementing those strategies. One of the important recommendations for each organization is to determine what knowledge it possesses, and then the way that enables the availability of that knowledge in the organization. The exchange of knowledge at the level of the organization affects the well-being as well as better mutual relations in the collective. Taught by new experiences, members of the organization are more productive, easier to overcome difficulties in work and better apply old knowledge in new challenges.
With this research, we come to the conclusion that organizations, regardless of their size and types of projects they are engaged in, apply knowledge management tools and techniques in order to acquire and improve their performance. The motive of every organization should be „knowledge is power", and with the proper use of knowledge they provide themselves with a high position.

\section{REFERENCES}

Garvin, D. A., Edmondson, A. C., \& Gino, F. (2008). Is yours a learning organizations?. Harvard Business Review, 86(3), pp. 10916, 134.

Garvin, D. (1993). Building a learning organization. Harvard abusiness Review.

Mihajlović, N., \& Apostolovska, M. (2019). Examining the impact of knowledge elements on the achievement of project benefits in project-oriented organizations. 5th IPMA SENET Project Management Conference, Advances in Economics, Business and Management Research, volume 108, DOI https://doi.org/10.2991/senet-19.2019.37.

Reich, B. H. (2007). Managing knowledge and learning in IT projects: A conceptual framework and guidelines for practice. Project Management Journal, 38(2), pp. 5-17.

Reich, B. H., Gemino, A., \& Sauer, C. (2012). Knowledge management and projectbased knowledge in it projects: A model and preliminary empirical results. International Journal of Project Management, 30(6), pp. 663-674.

Sveiby, K. E. (1996). What is Knowledge Management.

Villegas, R. (2000). Knowledge Management White Paper, KMPeer Publishing.

Žižić, M., Lovrić, M., \& Pavličić, D. (2003). Metodi statističke analize. Centar za izdavačku delatnost Ekonomskog fakulteta u Beogradu, Beograd.

Wunram, M., Weber, F., Pawar, K., Horton, A., \& Gupta, A. (2002). Proposition of a Human-centered Solution Framework for $\mathrm{KM}$ in the Concurrent Enterprise, International Conference on Concurrent Enterprising 